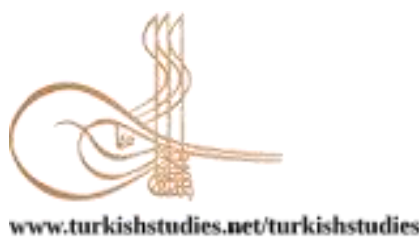

Turkish Studies

\title{
2000’li Yıllarda Çalışan Performansı Konusunda Yapılan Ulusal Makalelerin (Tr Dizin) Bibliyometrik Analizi
}

\author{
Bibliometric Analysis of National Articles (TR Index) in 2000's Regarding Employee Performance
}

\author{
İlknur Çevik Tekin* - Abdullah Türk**
}

\begin{abstract}
Employee performance is a concept that causes many organizational outputs. In order to evaluate employee performance, it is imperative that organizations measure and control the performance of employees. The main idea of this appraisal is to determine the activities of the employees, to identify the areas in which they are weak, to determine whether they fulfill their responsibilities, and to reveal whether they are exhibiting the correct flow as required by the job. Employees who do not perform the required performance are warned or disconnected from the job. In measuring the performance of the employee, the criteria formed by comparing the employee's approach to the determined goals and the performances achieved in the previous periods are used. The performance resulting from the working style and behavior of the employees is of great importance in achieving organizational goals. Since Hawthorne studies, studies have been carried out to increase employee performance. In this study, it was aimed to make bibliometric analysis of TR Index studies on "employee performance" between 2000-2020. Bibliometry is a research method that includes the analysis of processes and properties related to documents. Bibliometric studies carried out in Turkey, in general postgraduate dissertation thesis used the national database, and the types of articles in the journals studies discussed bibliometric analysis or field study is done. In this study, the journals that published the most articles on employee performance, the distribution of studies by year, the authors who received the most citations to a single study and the authors who received the most citations in total, the universities that contributed the most, the citation contributions of these University authors to their universities and other variables with which the studies were most associated were reported and interpreted.
\end{abstract}

Structured Abstract: Introduction: The most important issue that organizations should care about is employee performance. Performance is the ability to achieve results over a time defined by specific goals and priorities. Another aspect is the qualitative or quantitative determination of the efforts made and the results obtained for the realization of the goals. The criteria that measure the effectiveness and efficiency of the resulting result are the goals. If there is no target, neither the success of the employee nor the organization will

\footnotetext{
* Öğr. Gör. Dr., Selçuk Üniversitesi, Sosyal Bilimler Meslek Yüksekokulu, Yönetim ve Organizasyon, İşletme Yönetimi Lect. Dr., Selçuk University, Vocational School of Social Sciences, Management and Organization, Business Management ORCID 0000-0002-0802-1733

ilknurtekin@selcuk.edu.tr

**Dr. Öğr. Üyesi, İstanbul Gelişim Üniversitesi, İktisadi ve İdari Bilimler Fakültesi, Havacılık Yönetimi Asst. Prof. Dr, Istanbul Gelisim University, Faculty of Economics and Administrative Sciences, Aviation Management ORCID 0000-0002-2804-4203

abturk@gelisim.edu.tr

Cite as/ Atıf: Çevik Tekin, İ., \& Türk, A. (2021). 2000'li yıllarda çalışan performansı konusunda yapılan ulusal makalelerin ( $\mathrm{Tr}$ Dizin) bibliyometrik analizi. Turkish Studies, 16(2), 597-611.
} https://dx.doi.org/10.7827/TurkishStudies.50018

Received/Geliş: 19 March/Mart 2020

Accepted/Kabul: 25 April/Nisan 2021

Checked by plagiarism software

Published/Yayın: 30 April/Nisan 2021

CC BY-NC 4.0 
be measured. Organizations are only as good as employee performance (Çöl, 2008; Karaman, 2009). It is a set of values that employees ' behavior over a certain period of time gives the organization (Motowildo et al., 1997). It is a quantitative and qualitative description of where an individual, group, or enterprise doing a particular job can achieve with that job according to what it is intended, in other words, what it can provide (Artar and Bas, 1991: 13). As can be understood from these definitions, increasing employee performance is very important for organizations to gain a competitive advantage, as increases in individual employee performance will also increase organizational performance. Today's organizations know that the way to achieve organizational goals is through improving employee performance. The "system approach" that emerged in the 1950s was instrumental in the development of this idea. In the system approach, problems are divided into subsystems, each element is addressed in itself and the problem in the system is resolved. According to this approach, the system is a whole consisting of parts (Sabuncuoglu, 2005: 25).

Performance management of organizations is important in improving efficiency and efficiency and in harmonizing personal goals with organizational goals. In 1920-1930, when the classical management idea dominated the evaluation of employee performance, there was a clock-based performance evaluation. In these assessments, the ability to be "human", which was seen as a working machine, was ignored. In addition, the results of the evaluation of the employee who was evaluated for performance were not recorded in the employee's registry and were not shared with the employee. Later, thanks to the development of managerial psychology, performance criteria were considered based on success, and factors such as job satisfaction and motivation affected employee performance. In order to maximize the employee's work efficiency, it was understood that it is necessary to investigate the reasons underlying their behavior and behavior and to put forward solutions for this. Currently, performance management is seen as the key to achieving organizational goals, rather than a means of pressure that will scare the employee. Employees strive to maximize their individual performance if they believe that organizational goals are in the same direction as their individual goals. Goal alignment is important for organizations to build a proactive structure (Uyargil, 2013; Şener, 2015). Employee from a performance perspective, promotion of employees, salary, bonus, managers with guidance in making important decisions such as layoffs of employees to achieve the organizational goals with the high performance makes it to be (Ertan, 2008: 42).

\section{Research Problem}

This study aims to review a total of 221 studies on "employee performance" by bibliometric analysis.

\section{Research Questions}

1) How are the articles scanned in the TR Index on employee performance distributed by year?

2) Which journals publish the most articles on employee performance?

3) Which authors contribute to a single study on Employee Performance by receiving the most citations?

4) Which authors contribute to employee performance by receiving the most citations in total?

5) Which authors contribute to employee performance by publishing the most?

\section{Methodology}

The bibliometric analysis method, which is one of the quantitative analysis methods, was used in the study.

\section{Results and Conclusions}

The core of the research is the articles scanned in TR Index. The sample consists of articles between 2000 and 2021, when the first studies were conducted in the relevant field. Studies on employee performance at Trump were examined. Among them, the concepts of "Employee Performance", 'Employee Performance' and 'job performance' for bibliometric analysis were determined according to the Working Title, summary of the study and the fact that the study was passed in the key words. TR Index scanned as of 15.01.2021 was scanned for final control on 01.03.2021 and the data was updated, edited and ready for analysis. In these studies, it is observed that performance studies conducted on employees, especially in the last 5 Years, cover $63.34 \%$ compared to the previous 15 years. The data obtained were analyzed using statistical techniques in Excel. As a result of the study, there were publications in 116 different journals on employee performance. The most 
publications were in the Journal Business Research with 13 articles. According to the bibliometric analysis results, the most cited study on employee performance is the article titled "Effects of Perceived Empowerment on Employee Performance" by Çöl (2008) and published in Doğuş University Journal. Considering the relationship between the author and the content of this study and other studies, the total number of citations received from different studies indicates that the author has presented a publication that is qualified enough to be listed here. At this point, it was observed that 8 studies that received the most citations with a single study in the field received $38.21 \%$ of the total citations.In addition to the nature of these studies, since the areas represented by the studies in the summer are also important, the contents of these studies were examined and it was seen that these contents were made in the human resources management and organizational behavior literature rather than the fields in the "management strategy" determined by UAK. In addition, as a result of the relationship of common citations for all studies, it is seen that $29.22 \%$ of the 1078 citations obtained after the duplicates are removed, that is, almost 1 in 3 belongs to the researchers who published the most. However, when the authors and their publications are evaluated, 35 of 221 publications have the names of 10 researchers.

Keywords: Management, Human Resource, Employee Performance, Bibliometric Analysis, TR Index.

Öz: Çalışan performansı pek çok örgütsel çıktıya neden olan bir kavramdır. Çalışan performansını değerlemek için örgütler tarafından çalışanların sergiledikleri performansların ölçülüp, denetiminin yapılması zorunludur. $\mathrm{Bu}$ değerlemenin amacı, çalışanların yaptıkları faaliyetleri belirleyip, zayıf kaldıkları alanları tanımlamak, sorumluluklarını yerine getirip getirmediklerinin tespitinin yapılması ve işin gerektirdiği şekilde doğru bir akış sergileyip, sergilemediğini ortaya koymaktır. Gerekli performans sergilemeyen çalışanların uyarılması ya da iş ile ilgili bağlantısının kesilmesi sağlanır. Çalışan performansının ölçülmesinde, çalışanın belirlenen hedeflere ne derece yaklaştığı ve önceki dönemlerde elde ettiği performanslarının kıyaslanması sonucu oluşan kriterler kullanılır. Çalışanların, çalışma şekli ve davranışları sonucu ortaya çıkan performansın örgütsel amaçlara ulaşmada önemi büyüktür. Hawthorne çalışmalarından günümüze, çalışan performansının arttırılması ile ilgili çalışmalar yapılmaktadır. Bu çalışmada 2000-2020 yılları arasında "çalışan performansı" konusunda yapılan TR Dizin çalışmaların bibliyometrik analizinin yapılması amaçlanmışıı. Bibliyometri, dokümanlar ile ilgili süreçlerin ve özelliklerin analiz edilmesini içeren bir araştırma yöntemidir. Türkiye'de gerçekleştirilen bibliyometrik çalı̧̧malarda, lisansüstü tez çalışmalarında genel olarak ulusal tez veri tabanı kullanılırken, makale türünde ele alınan bibliyometrik çalışmalarda ise dergi incelemesi ya da alan incelemesi yapılmaktadır. $\mathrm{Bu}$ çalışmada, çalışan performansı konusunda en çok makale yayınlayan dergiler, çalışmaların yıllara göre dağılımı, tek bir çalışmaya en çok atıf alan yazarlar ve toplamda en çok atıf alan yazarlar, en çok katkı sunan üniversiteler, bu üniversite yazarlarının üniversitelerine atıf katkıları ve çalışmaların en çok ilişkilendirildiği diğer değişkeneler tespit edilerek elde edilen sonuçlar raporlanıp, yorumlanmıştır.

Anahtar Kelimeler: Yönetim, İnsan Kaynakları, Çalışan Performansı, Bibliyometrik Analiz, TR Dizin.

\section{Giriş}

Örgütlerin önem vermeleri gereken en önemli husus çalışan performansıdır. Performans, belirli amaç ve önceliklere göre tanımlanan bir zaman içerisinde sonuçlar elde etme yeteneğidir. Diğer bir açıdan ise ve amaçların gerçekleştirilmesi için sarf edilen çabaların ve elde edilen sonuçların nitel ya da nicel olarak belirlenmesidir. Elde edilen sonucun etkinliğini ve verimliliğini ölçen kriter hedeflerdir. Hedef olmaz ise ne çalışanın ne de örgütün başarısı ölçülemeyecektir. Örgütler ancak çalışanların performansları kadar iyidir (Çöl, 2008; Karaman, 2009). Çalışanların belirli bir zaman diliminde gerçekleştirdiği davranışların örgüte kazandırdığı değerler bütünüdür (Motowildo vd., 1997). Spesifik bir görevi olan kişi, bir grup ya da bir teşebbüsün o iş ile amaçlanana göre amacına ne kadar ulaşabildiği diğer bir deyişle, ne çıktılar sunduğunun nicel ve nitel olarak anlatımıdır (Artar ve Bas, 1991: 13). Bu tanımlardan da anlaşılabileceği gibi çalışanların bireysel performanslarındaki artışlar, örgütsel performanslarda da artış sağlayacağı için örgütlerin rekabet avantajı elde etmelerinde için çalışan performanslarının artırılması çok önemlidir. Günümüz örgütleri, örgütsel amaçlara ulaşmanın yolunun çalışanların performanslarının arttırmasından geçtiğini bilmektedirler. Bu düşüncenin gelişiminde 1950'li yıllarda ortaya çıkan "sistem yaklaşımı" 
etkili olmuştur. Sistem yaklaşımında sorunlar alt sistemlere ayrılarak, her öge kendi içinde ele alınarak sistemdeki sorun giderilmektedir. Bu yaklaşıma göre sistem, parçalardan meydana gelen bir bütündür (Sabuncuoğlu, 2005: 25).

Örgütlerin performans yönetimi etkinliği ve verimliliği arttırma ve örgütsel amaçlarla kişisel amaçların uyumlaştırılmasında önemlidir. Çalışan performansını değerlemede klasik yönetim düşüncesinin hâkim olduğu 1920-1930 senelerinde saat bazlı bir performans değerlendirme söz konusuydu. Bu değerlendirmelerde çalışan bir makine gibi görülmüş "insan" olma özelliği göz ardı edilmiştir. Ayrıca performans değerlendirmesi yapılan çalışanın değerlendirme sonuçları çalışanın siciline işlenip, çalışan ile paylaşılmamaktaydı. Daha sonraları yönetsel psikolojinin gelişimi sayesinde performans kriteri başarı bazlı ele alınıp, iş tatmini, motivasyon gibi faktörlerin çalışan performansını etkilediği ortaya çıkmıştır. Çalışanın iş verimliliğinin maksimum seviyeye çıkarılması için davranışlarının ve davranışların temelinde yatan nedenlerin araştırılarak buna yönelik çözüm önerilerinin ortaya konulmasının gerekliliği anlaşılmıştır. Günümüzde ise performans yönetimi çalışanı korkutacak bir baskı aracı olmaktan öte örgütsel amaçlara ulaşmanın anahtarı olarak görülmektedir. Çalışanlar, örgütsel amaçların bireysel amaçlarıyla aynı yönde olduğuna inanırlarsa bireysel performanslarını maksimum seviyeye çıkarmak için çaba gösterirler. Örgütlerin proaktif bir yapıya kavuşturması için amaç uyumu önemlidir (Uyargil, 2013; Şener, 2015). Çalışan performansı diğer bir açıdan, çalışanlara dair terfi, maaş, prim, işten çıkarma gibi önemli kararların alınmasında yöneticilere yol göstermekle birlikte çalışanların yüksek performansa sahip olmaları örgütsel hedeflere ulaşmayı kolaylaştırmaktadır (Ertan, 2008: 42). Bu çalışmada 2000'li yıllarda "çalışan performansı" konusunda yapılan TR Dizin çalışmaların bibliyometrik analiz yöntemi ile incelenmesi amaçlanmiştır.

\section{Araştırma Metodolojisi}

Bibliyometrik analiz literatürde yapılmış çalışmaların gelişim seviyelerini daha iyi bir noktaya çıkarma amacıyla araştırmalara geniş bir bakış açısıyla bakma firsatı sağlayan multidisipliner bir temel dayanak noktasıdır (Samiee ve Chabowski, 2012;369). Bu açıdan değerlendirildiğinde bibliyometrik araştırmaların hem nitel hem nicel açıdan değerlendirilmesine olanak sağladığı söylenebilir (Al ve Soydal, 2012). Bibliyometrik araştırmalarda amaç; ilgili araştırma alanı içinde yapılan çalışmaların zaman içindeki hızı geşiminin yönü, yayınların yapıldığı kurumların izledikleri politikalar ve durum değerlemesinin yapılmasıdır. Bibliometrik analiz çalışma yapılan ülklerin o alanda periyodik incelenmesi kapsamında gelişim yönü bilimsel altyapısı ve belirlediği bakış açısını anlayabilmek ve buna göre bir yön çizebilmek için önem arz etmektedir. Bu analiz aynı zamanda araştırma yapılan alan ya da konu hakkında performansa dair bir bakış açısı oluşturacağı dolayısıyla ilgili alana bağlı olarak farklı değerlendirmeler yapabilme firstı da sunmaktadır (Al, vd., 2012). Bu yöntem özünde araştırmaların etkilerine ve saygınlıklarına göre tasnif etmeye dayalı bir araştırma yöntemidir (Hall, 2011, s. 16). Biblometrik analizlerin kullanıldığ1 programlar açısından farklı verilerden alana özgü katkı sunacağı düşünülen tablolar da yapılabilmetedir. Ancak alan ve konu ne olursa olsun bu yöntem için genel geçer olarak kullanılan en önemli ve temel alt analiz atıf analizidir.

Atıf analizi araştırmacıların dergi ve/veya yayımcı kuruluşların ve ilgili alanda yapılmış çalışmaların gerek nicelik gerekse de nitelik yönünden belirlenebilmesi, bilimsel gelişmelere ilgili alanlardan bir model oluşturulmasına yardımcı olabilmektedir. Bu analizde, ortaya koyulan araştırma sonuçları ilgili alanda metrik bilgilere ulaşılmasına yönelik her türlü çalışmanın ortaya koyulmasıdır (Bayram, 1998: 23). Atıf analizinin detayında ilgili araştırmaya yönelik en çok yararlanılmış kaynakların saptanması ilgili alanda alanlardaki literatürün gelişim sürecini saptamada ve yine ilgili alana dair yayın yapılan dergilerin belirlenmesinde çok önemli bilgiler aktarılmaktadır (Tatar ve Ece, 2012: 1). Bibliyometrik analizin bir diğer amacı ise; ortak eşleşme, tek bir çalışmaya birden fazla 
atıf, birden fazla çalışmaya toplam atıf ve yazarların bu çalışmalarla olan bağlantılarını ortaya koymaktır.

Bir alandaki atıf temelli analizlerin yapılması, bir disiplindeki veya bir bilimsel alandaki önemli gelişmeleri tanımaya yardımcı olmaktadır. Bibiliyometrik analizde kullanılan bir diğer analiz bibliyografik eşleştirme ve ortak atıf analizidir. Bu noktada üretilen bulgular sonucunda araştırmacıların ortaya koymuş oldıuğu çalışmalara diğer araştırmacılar tarafindan referans gösterilme temeline dayanmaktadır (Liuch vd, 2009). Bibliyometrik analizin sayısal veriler üzerinden aktarılması sonucu nicel bir analiz olduğu bilinmektedir. Bu noktada araştırmayı desteklemek için nitel bir program olan Maxqda 20 programında ilgili alanda yapılmıș tüm çalışmaların başlıkları da kelime bulutu analizine tabi tutularak farklı bir bakış açısı oluşturulmaya çalışılmıştır.

\section{Yöntem}

Bu çalışmada Türkiye'de 'Çalışan Performansı" konusu ULAKBİM TR Dizin'de taranan makaleler bibliyometrik analiz yöntemi ile incelenmiştir. Bu araştırma ile şu araştırma sorularına yanıt aranmıştır;

1. Çalışan performansı konusunda TR Dizinde taranan makalelerin yıllara göre dağılımı nasildir?

2. Çalışan performansı konusunda en çok makale yayınlayan dergiler hangileridir?

3. Çalışan performansı konusunda tek bir çalışmaya en çok atıf alarak katkı sağlayan yazarlar hangileridir?

4. Çalışan performansı konusunda toplamda en çok atıf alarak katkı sağlayan yazarlar hangileridir?

5. Çalışan performansı konusunda en çok yayın yaparak katkı sağlayan yazarlar hangileridir?

Soruların amacı; literatür içerisinde ilgili konunun önem kazandığı dönemleri ön plana çıkarabilmek, araştırma konusunda özellikle alanda araştırma yapacak olan yazarlara bu araştırmaları destekleyen dergileri ön plana çıkararak araştırmacılara zaman yönetimi konusunda bakış açısı sunmak, bu alanda ön plana çıkan araştırmacıların tespitinin yapılarak alanda araştırma yapacak çalışmacılara niteliksel bir bakış açısı oluşturmaktır. $\mathrm{Bu}$ noktada çalışmanın gelecekteki araştırmalara ve araştırmacılara yol göstermesi ve bir bakış açısı sağlaması önem arz etmektedir.

Araştırmanın özünü TR Dizin'de taranan makaleler oluşturmaktadır. Örneklemi ise çalışan performansı konusunda ilk çalışmaların yapıldığı 2000 ile 2021 yılları arasındaki makaleler oluşturmaktadır. TR Dizin taratıldığında çalışan performansı konusunda yapılmış çalışmalar incelenmiştir. Bu çalışmalar "çalışan performansı", "işgören performansı" ve "iş performansı", kavramları çalışma başlığı, çalışmanın özeti ve çalışmanın anahtar kelimeleri içinde geçmesi durumuna göre belirlenmiş ve analize dahil edilmiştir. Söz konusu anahtar kelimeler TR Dizin'de taranmış ve çalışmalar arasında tekrar edenler çıkartılmıştır. 15.01.2021 tarihi itibari ile taranan TR Dizin, 01.03.2021 tarihinde son kontrol amaçlı taranmış ve veriler güncellenmiş, düzenlenmiş, analize hazır hale getirilmiştir. Bunun sonucunda çalışan performansı konusunda 221 makale toplanmıştır. Bibliyometrik analiz sürecinde veriler içerik analizi yöntemi ile güvenilirliğin sağlanabilmesi için iki araştırmacı tarafından çalışmaların yılları, en çok çalışma yapan yazarlar en çok atıf alan çalışma ve bu çalışmaların yapıldığı dergilere göre incelemiştir. Araştırmaya dahil edilen çalışmalar ayrıca, yazar sayılarına, aynı yazara ait birden fazla yayınlara, bu yayınların toplamda aldığı atıf sayılarına göre kodlanmış ve analiz edilerek bulgular kısmında yorumlanmıştır.

\section{Bulgular}

\section{Yıllara Göre Dağılım}


Tablo 1'de Çalışan performansı konusunda TR Dizinde taranan makalelerin yıllara göre dağılımı verilmiştir.

Tablo 1: Y1llara Göre Dağılım

\begin{tabular}{cc}
\hline Yayın Yılı & Yayın Sayıs \\
\hline 2020 & 22 \\
2019 & 40 \\
2018 & 29 \\
2017 & 16 \\
2016 & 13 \\
2015 & 20 \\
2014 & 12 \\
2013 & 9 \\
2012 & 5 \\
2011 & 3 \\
2010 & 15 \\
2009 & 9 \\
2008 & 8 \\
2007 & 7 \\
2006 & 5 \\
2005 & 2 \\
2004 & 2 \\
2003 & 2 \\
2002 & 0 \\
2001 & 1 \\
2000 & 1 \\
\hline
\end{tabular}

Bu kapsamda yapılan çalışmalarda 2002 yılında hiç yayın yapılmadığı görülürken en çok yayının 2019 yılında (40) olduğu görülmektedir. Ancak genel çerçeve de değerlendirildiğinde bibliyometrik analiz kapsamına 2000 yılı ile 2020 yılları kapsamında yapılan araştırmalar dâhil edilmiştir. Bu tarih aralığında TR Dizin'de mükerrer kayıtlar çıkarılınca 221 çalışmaya ulaşılmıştır. Çalışan performansı konusunda yapılan çalışmalara bakıldığında genellikle örgütsel alanda çalışanın iş yeri ve örgüt ilişkisini baz alan yönetim strateji alanı içinde "İnsan Kaynakları Yönetimi" yazınında yapıldığı görülmüştür. Bununla birlikte çalışma sayılarının 2009 yılına dek çok net artış1 gözlemlenmemiş olsa da 2015 yılından itibaren belli bir seviyenin altına düşmediği ve son yıllarda çalışan performansının, yazında daha çok çalışıldığı görülmüştür.

\section{Dergilere Göre Dağılım}

TR Dizin veri tabanında alan yayımlanan makalelerin dergilere göre sayısal dağılımı Tablo 2'de yer almaktadır. 
Tablo 2: Dergilere Göre Dağılımı

\begin{tabular}{lc}
\hline Dergi Adı & Yayın Sayısı \\
\hline İşletme Araştırmaları Dergisi & 13 \\
Business and Management Studies: An International Journal & 7 \\
Öneri Dergisi & 6 \\
Anatolia: Turizm Araştırmaları Dergisi & 5 \\
Anemon Muş Alparslan Üniversitesi S.B.D. & 5 \\
Atatürk Üniversitesi İ.İ.B.D. & 5 \\
Eskişehir Osmangazi Üniversitesi İ.İ.B.D. & 5 \\
Gazi Üniversitesi Ticaret ve Turizm Eğitim Fakültesi Dergisi & 5 \\
Journal of Tourism and Gastronomy Studies & 5 \\
Yönetim ve Ekonomi: Celal Bayar Üniversitesi İ.İ.B.D. & 5 \\
Çukurova Üniversitesi Sosyal Bilimler Enstitüsü Dergisi & 4 \\
\hline
\end{tabular}

2000-2020 yılları arasında çalışan performansı konusunda 116 farklı dergide yayın yapıldığı tespit edilmiştir. Bu dergiler incelendiğinde ilk sırada 13 makale yayını ile İșletme Araştırmaları Dergisi'nin yer aldığı görülmektedir. Bunu sırasıyla, 7 makale ile Business and Management Studies: An International Journal ve 5'er makale ile Öneri Dergisi, Anatolia: Turizm Araştımaları Dergisi, Anemon Muş Alparaslan Üniversitesi S.B. Dergisi, Atatürk Üniversitesi İ.İ.B. Dergisi, Eskişehir İ.İ.B. Dergisi, Gazi Üniversitesi, Ticaret ve Turizm E.F. Dergisi, Journal of Tourism and Gastronomy Studies ve Yönetim ve Ekonomi: Celal Bayar Üniversitesi İ.İ.B.F Dergisi'nin takip ettiği görülmektedir. Bu noktada Çukurova Üniversitesi Sosyal Bilimler Enstitüsü Dergisi’nin 4 yayını görülmekte ve bu aşamadan sonra diğer 100 kadar dergide genellikle tek ya da iki yayın yapıldığı görülmüş̧ür.

\section{Tek Çalışmaya En Çok Atıf Almış Yazarlara Göre Dağılım}

TR Dizin veri tabanında yer alan makalelere göre tek çalışmayla en çok atıf almış yazarlara göre sayısal dağılım Tablo 3’te yer almaktadır.

Tablo 3: Tek Çalışmaya En Çok Atıf Almış Yazarlara Göre Dağılım

\begin{tabular}{|c|c|c|c|c|c|c|}
\hline Makale Adı & Yazarlar & Yil & Dergi & & $\begin{array}{l}\text { Araştırma } \\
\text { Yöntemi }\end{array}$ & $\begin{array}{l}\text { Atıf } \\
\text { Sayısı }\end{array}$ \\
\hline $\begin{array}{l}\text { Algilanan } \\
\text { güçlendirmenin } \\
\text { işgören performans1 } \\
\text { üzerine etkileri }\end{array}$ & Güner Çöl & 2008 & $\begin{array}{l}\text { Doğuş } \\
\text { Dergisi }\end{array}$ & Üniversitesi & Nicel & 93 \\
\hline
\end{tabular}


Çalıșanların

algıladıkları örgütsel destek ve iş stresinin örgütsel özdeşleşme ve iş performansına etkisi

Psikolojik sermayenin iş tatmini, iş performansı ve işten ayrilma niyeti üzerindeki etkisine yönelik bir araştırma

Çalışma Ortamında Duygusal Zekâ: İş Performans1, İş

Tatmini, Örgütsel Vatandaşlık Davranışı ve Bazı Demografik Özelliklerle İlişkisi

Örgütlerde gelişim kültürü ve algılanan örgütsel desteğin iş tatmini ve iş performansina etkisi: Güvenin aracılık rolü

Örgütsel iklimin işgören performansı üzerine etkisi: OSTIMM imalat işletmeleri çalışanları üzerine bir araştırma

Örgüte Duygusal, Devamlilık ve Normatif Bağlılık ile iş

Performans1

Arasındaki İlişkinin İncelenmesi

Örgütsel Adalet: Ortaya Çıkışı, Kuramsal Yaklaşımlar ve Bugünkü Durumu

Öğretmenlerin iş doyum algiları ile performansları

arasındaki ilişkinin

belirlenmesine yönelik

bir araştırma

\section{Ömer Turunç;}

Mazlum Çelik

2010 Yönetim ve Ekonomi: Nicel Celal Bayar Üniversitesi İ.İ.B.F.D.

Ahmet Erkuş;

Mine Mukaddes

Afacan Findiklı

Sait Gürbüz;

Murad Yüksel

2008

Doğuş
Dergisi

Üniversitesi Nicel

$2013 \begin{aligned} & \text { İstanbul Üniversitesi Nicel } \\ & \text { İşletme F.D. }\end{aligned}$

$2013 \begin{aligned} & \text { İstanbul Üniversitesi Nicel } \\ & \text { İşletme F.D. }\end{aligned}$
69

69

45

İrfan Akkoç; 2012 Yönetim ve Ekonomi: Nicel Abdullah Çalışkan, Celal Bayar Üniversitesi Ömer Turunç İ.İ.B.F.D.

Hasan Tutar;

2010

Ankara Üniversitesi SBF Nicel

30

Mehmet Altınöz Dergisi

2008 İstanbul Üniversitesi Nicel 30 İşletme F.D.

2004 Türk Psikoloji Yazıları Nitel

Hakan Koç;

2009 Ondokuz May1s Nicel 28 İrfan Yazıcıŏlu; Hüseyin Hatipoğlu

43

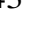

0

Uysal Doruk Irak

Universitesi Eğitim

Fakültesi Dergisi

2000-2020 yılları arasında çalışan performansı konusunda Güner Çöl'ün 2008 yılında Doğuş Üniversitesi Dergisi’nde yayınlanan 'Algılanan Güçlendirmenin İşgören Performansı Üzerine Etkileri’” isimli çalışmanın 93 atıfla ilk sırada yer aldığı görülmektedir. Yazarı 69 atıf ile 
Ömer Turunç ve Mazlum Çelik'in 2010 yılında 'Çalışanların Algıladıkları Örgütsel Destek ve İş Stresinin Örgütsel Özdeşleşme ve İş Performansına Etkisi'” isimli çalışması ve Ahmet Erkuş ve Mine Mukaddes Afacan Fındıklı'nın 'Psikolojik Sermayenin İş Tatmini, İş Performansı ve İşten Ayrılma Niyeti Üzerindeki Etkisine Yönelik Bir Araştırma" isimli çalışması takip etmektedir. Bu sıralama Hakan Koç, İrfan Yazıcıoğlu, Hüseyin Hatipoğlu'nun 28 atıf aldığı 2009 yılında yapmış olduğu 'Öğretmenlerin iş doyum algıları ile performansları arasındaki ilişkinin belirlenmesine yönelik bir araştırma' ' isimli çalışmaya kadar 43, 42, ve 30'ar atıflı 3 çalışma ile sürmüş bu sıradan sonra 20'li haneler ve 10'lu hanelerin çokça olduğu farklı çalışmalar ile devam etmiştir. Atıf sayılarının belirlenmesinde yine Tr Dizin dergilerde yapılan atıflar baz alınmıştır. Ayrıca bu çalışmalardan "Öğretmenlerin iş doyum algıları ile performansları arasındaki ilişkinin belirlenmesine yönelik bir araştırma" isimli çalışmanın nitel, diğerlerinin ise nicel olduğu görülmektedir.

\section{En çok Yayın Yapılan Kurumlara Göre Dağılım}

2000-2020 yılları arasında TR Dizin veri tabanında yer alan makalelere göre en çok yayın yapılan kurumlara göre dağılım sayısal dağılım Tablo 4'de yer almaktadır.

Tablo 4: En çok Yayın Yapılan Kurumlara Göre Dağılım

\begin{tabular}{lc}
\hline KURUM ADI & YAYIN \\
SAYISI \\
\hline Gazi Üniversitesi & 13 \\
Hacettepe Üniversitesi & 13 \\
Kara Harp Okulu & 11 \\
Kocaeli Üniversitesi & 9 \\
İstanbul Üniversitesi & 7 \\
Marmara Üniversitesi & 7 \\
Trakya Üniversitesi & 7 \\
İstanbul medeniyet üniversitesi & 6 \\
Mersin Üniversitesi & 6 \\
\hline
\end{tabular}

Tablo 4'de çalışan performansı konusunda ulusal veri tabanında yer alan makalelere göre en çok yayın yapan yazarların çalışmış olduğu kurumlara bakıldığında 13'er yayın ile Gazi Üniversitesi ve Hacettepe Üniversitesi araştırmacılarının ilk sırayı paylaştı̆g görülmektedir. Bu üniversiteleri Kara Harp Okulu 11 yayınla takip ederken, Kocaeli Üniversitesi, İstanbul Üniversitesi, Marmara Üniversitesi, Trakya Üniversitesinin takip ettiği görülmektedir. Bu tablodan da anlaşılacağ 1 üzere en çok yayın yapan yazarların kurumlarına bakıldığında ilk sıralarda yer alan 37 yayının Ankara ve İstanbul illerindeki kurumlarda yapıldığı anlaşılmaktadır. Bu veriler ışığında ilgili konuda özellikle metropol şehirlerde çalışma yaoğunluğu, nispeten daha küçük bölgelerde çalışma eksikliği dikkat çekicidir. Nitekim daha çok yayın yapılmış en üstteki kurumlara bakıldığında neredeyse \%80'nin bahse konu metropol şehirlere ait kurumlar olduğu dikkat çekmektedir.

\section{Yayınlara En Çok Atıf Alan Kurumlar}

2000-2020 yılları arasında TR Dizin veri tabanında yer alan makalelere göre yayınlara en çok atıf alan kurumlar göre dağılım sayısal dağılım Tablo 5'de yer almaktadır. 
Tablo 5: Yayınlara En Çok Atıf Alan Kurumlar

\begin{tabular}{lc}
\hline KURUM ADI & ATIF SAYISI \\
\hline Kara Harp Okulu & 205 \\
Gazi Üniversitesi & 120 \\
Balıkesir Üniversitesi & 93 \\
Hacettepe Üniversitesi & 84 \\
Afyon Kocatepe Üniversitesi & 67 \\
Gelişim Üniversitesi & 48 \\
Gedik Üniversitesi & 45 \\
Kara Kuvvetleri Komutanlığı & 43 \\
Sakarya Üniversitesi & 40 \\
Gebze Yüksek Teknoloji & 24 \\
\hline
\end{tabular}

Bu kapsamda 2000-2020 yılları arasında çalışan performansı konusunda ulusal veri tabanında yer alan makalelere göre yayınlara en çok atıf alan kurumlara bakıldığında Kara Harp Okulu araştırmacıları yapmış oldukları yayınlara toplam 205 atıf alarak ilk sırada yer almaktadır. Takip eden atıf sıralamasına bakıldığında Gazi Üniversitesi, Balıkesir Üniversitesi, Hacettepe Üniversitesi, Afyon Kocatepe Üniversitesi ile devam etmektedir. Ancak son sırada Gebze Yüksek Teknoloji Üniversitesine gelindiğinde bir önceki sıraya göre neredeyse yarı yarıya bir düşüş olmaktadr. Bu aşamadan takip edildiğinde çok ciddi bir düşüş olduğunu ve devamında gelen çalışmaların genel olarak tek atıf alan çalışmalar ya da atıf almayan çalışmalar olduğu görülmektedir.

\section{Birden Çok Çalışmayla En Çok Atıf Alan Yazarlara Göre Dağılım}

TR Dizin veri tabanında yer alan makalelere göre çalışan performansı konusunda, 2000-2020 yılları arasında en çok çalışma yapmış yazarlara göre sayısal dağılım Grafik 1'de yer almaktadır. 


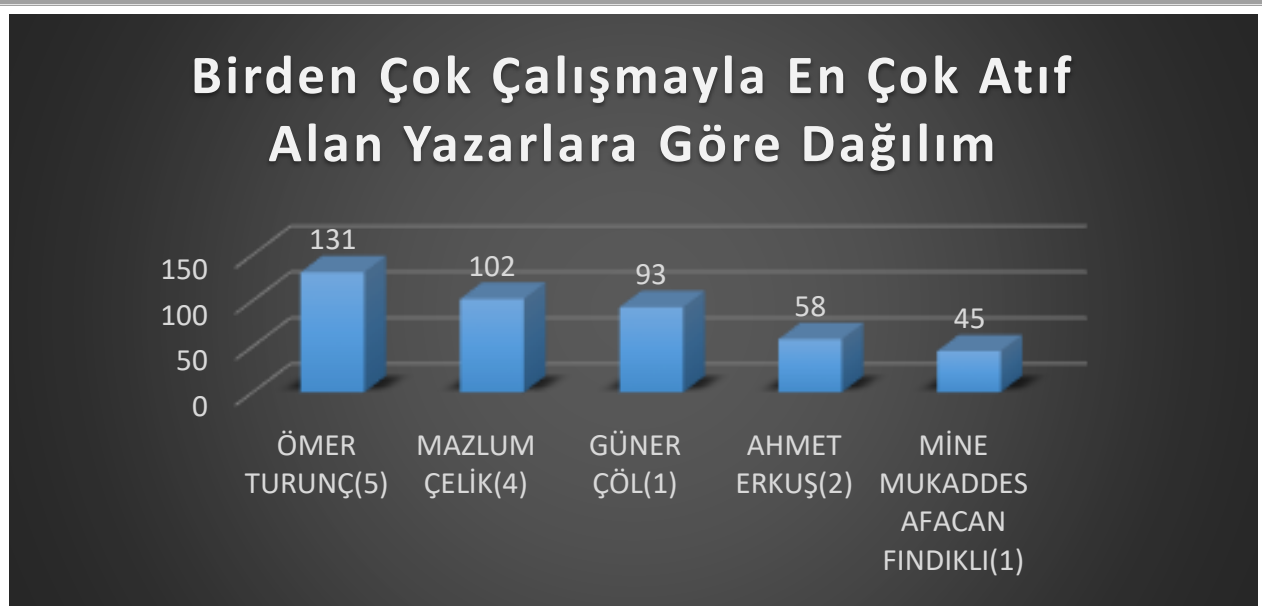

Grafik 1. Birden Çok Çalışmayla En Çok Atıf Alan Yazarlara Göre Dağılım

Çalışan performansı konusunda 2000-2020 yılları arasında birden çok çalışma ile en çok atıf sayısının toplamda 5 çalışması olan ancak bunlardan 1'inde hiç atıf alamamış olmasına rağmen 5 farklı çalışma ile (131) Ömer Turunç'a ait olduğu görülmektedir. Bu çalışmalardaki dağılım 2010 Y11ı 'Çalışanların Algıladıkları Örgütsel Destek ve İş Stresinin Örgütsel Özdeşleşme ve İş Performansına Etkisi'" 2 yazarlı 69 atıf, 2012 yılı 'Örgütlerde Gelişim Kültürü ve Algılanan Örgütsel Desteğin İş Tatmini ve İş Performansına Etkisi: Güvenin Aracılık Rolü' 3 yazarlı 42 atıf, 2010 y1l ' Organizasyonlarda Kontrol Algılamalarının Örgütsel Özdeșleșme ve İș Performansına Etkisi" 16 tek yazarlı atıf, 2009 yılı "Aile-İş̧ Çatışması, İş Stresi ve Örgütsel Sadakatin İş Performansına Etkisi: Savunma Sektöründe Ampirik Bir Çalışma" 2 yazarlı 4 atıf olarak görülmektedir. Bu noktada yazarların birlikte çalışma ilişkisinin de getirisi olarak 102 atıf ile Mazlum Çelik'in yine 4 farklı çalışmasından ki bu çalışmaların 2'si Ömer Turunç ile yaptıkları çalışmadan 2. Sırada olduğu görülmektedir. Yine devamında bir önceki grafikte tek çalışma ile en çok atıf alan Güner Çöl'ün bu çalışması ile 93 atıfla 3. Sırada olduğu, bunları ise tek çalışmaya alınan en çok atıfta 3. Sırada yer Ahmet Erkuş'un 58 atıfla 4. Sırada ve yine tek çalışmaya en çok atıf grafikte 3. Sırada ve Ahmet Erkuş ile birlikte yer alan Mine Mukaddes Afacan Fındıklı'nın 45 Atıfla 5. Sirada yer aldığı görülmektedir.

\section{En Çok Yayın Yapan Yazarlara Göre Dağılım}

2000-2020 yılları arasında TR Dizin veri tabanında yer alan makalelere göre çalışan performansı konusunda en çok çalışma yapmış yazarlara göre sayısal dağılım Grafik 2'te yer almaktadir. 


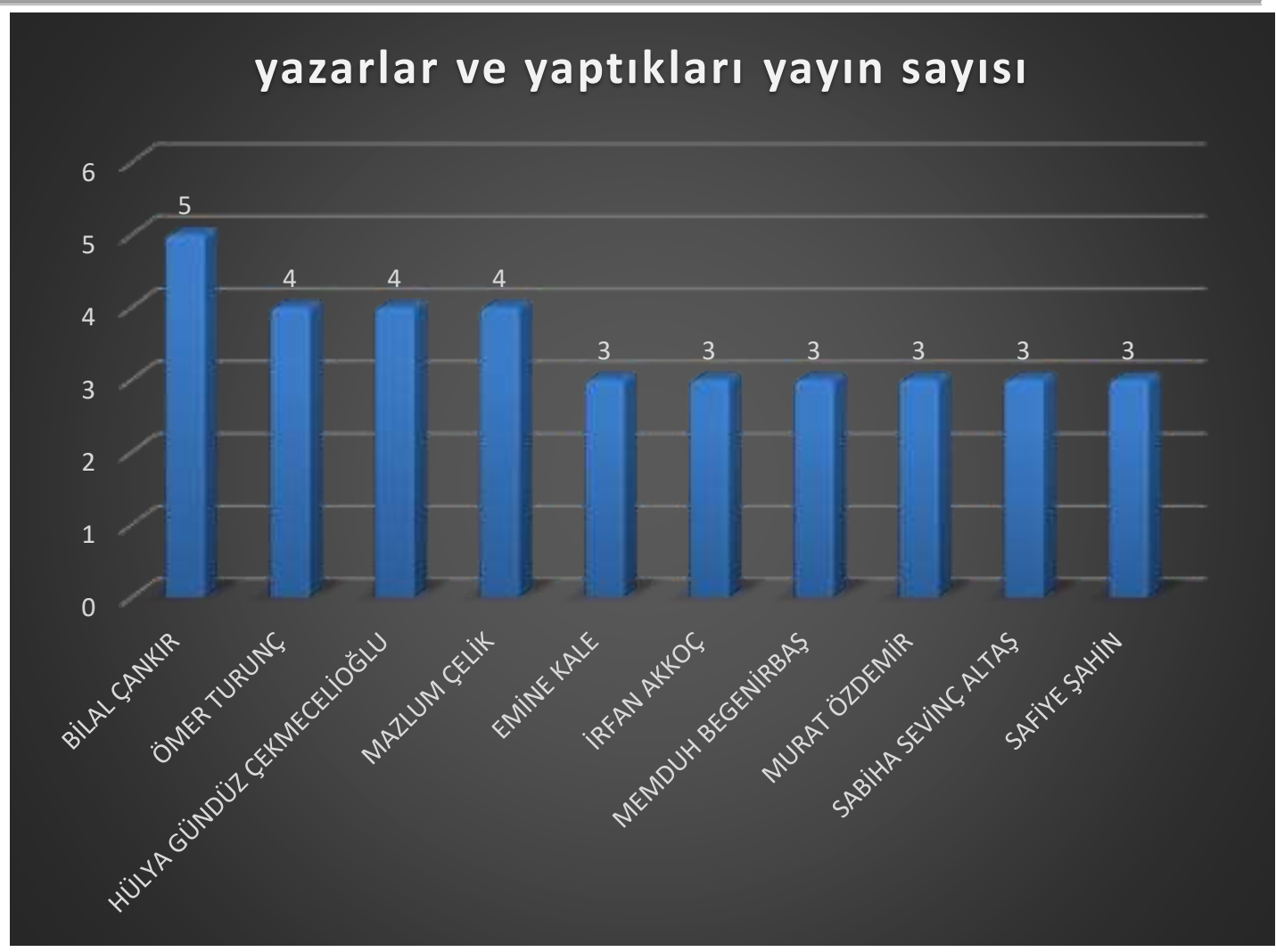

Grafik 2. En Çok Yayın Yapan Yazarlara Göre Dağılım

2000-2020 yılları arasında çalışan performansı konusunda yapılan 221 çalışmaya en çok katkı sağlayan yazarların, 5'er çalışma ile Bilal Çankır ve Ömer Turunç olduğu görülmekle birlikte, yazarların ortak çalışması bulunmamaktadır. Özellikle çalışma sayısı en çok olan yazarlardan Ömer Turunç'un Grafik 3 ve Grafik 4'te görüleceği üzere atıf alma konusunda ön plana çıkan çalışmalarının olduğu görülürken Bilal Çankır'ın bahse konu grafiklerde olmadığı görülmektedir. Konu üzerinde en çok yayın yapan 3. yazarın Hülya Gündüz Çekmecelioğlu'nun üç çalışmasının ikisi 9. Surada yer alan Sabiha Sevinç Altaş ile birliktedir. En çok çalışma yapan 4. Surada yer alan Mazlum Çelik'in iki çalışması grafikte 2. Sırada yer alan Ömer Turunç ile birliktedir. Grafikte yer alan Emine Kale'nin üç çalışması da listedeki diğer çalışmacıların araştırmalarından farklı kişiler ile birliktedir. Grafikte 5. Sırada yer alan İrfan Akkoç'un üç çalışmasından bir tanesi Grafikte 2. Sırada yer alan Ömer Turun ile birliktedir. Grafikte yer alan 6. Sırada yer alan Memduh Begenirbaş'ın üç çalışması da listedeki diğer çalışmacıların araştırmalarından farklı kişiler ile birliktedir. Yine grafikte yer alan 7. Sırada yer alan Murat Özdemir'in üç çalışması da listedeki diğer çalışmacıların araştırmalarından farklı kişiler ile birliktedir. Grafikte yer alan 10. sırada yer alan Safiye Şahin'in üç çalışmasının tamamı grafikte 1. sırada yer alan Bilal Çankır ile birliktedir.

\section{Yayımlanmış Makalelerin Başlıklarına Göre Kelime Bulutu Analizi}

Bu kapsamda 2000-2020 yılları arasında TR Dizin veri tabanında yer alan makalelerin başlıklarına göre yapılmış kelime bulutu analizi Şekil 1'de yer almaktadır. 


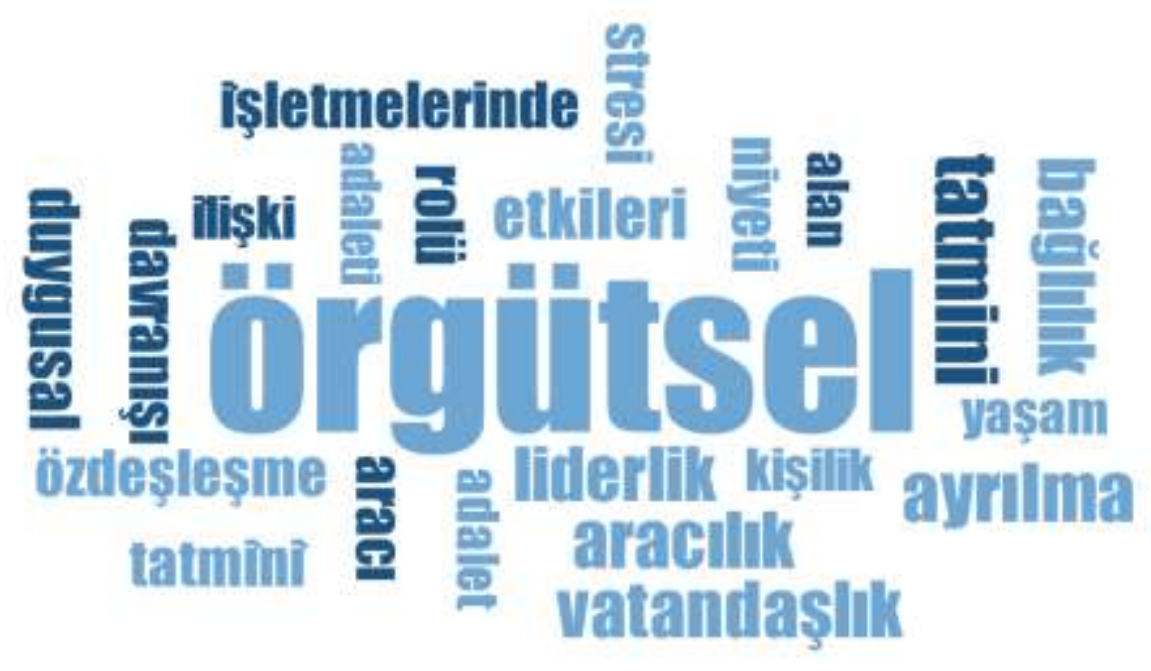

Şekil 1. Kelime Bulutu

TR Dizin taramaları sonucunda elde edilen çalışmaların başlıkları MAXQDA 20 programına aktarılmış ve başlıklarda kullanılan sözcüklerden bir kelime bulutu elde edilmiştir. Kelime bulutu başliklarda en çok tekrar edilen kelimelerden düzenlenmiştir. "Çalışan performansı, işgören performansı, iş performansı" kavramları her başlıkta kullanıldığı için çıkartılmıştır. Bunun dışında kalan kelimelere bakıldığında "örgütsel" kelimesi bulutun en ortasında yer almaktadır. Bu noktada çalışan performansı konusunun organizasyonel düzeyde yapıldığı anlaşılmaktadır. Bunun dışında kullanılan "duygusal, tatmin, bağl1lık, liderlik, vatandaşlık, özdeşleşme, davranış, yaşam" gibi kelimelerin çalışan performansı ile bu değişkenlerle ilişkilendirlerek kullanıldığı görülmektedir. Bu veriler 1şığında ilgili konuda yeni araştırma yapacak çalışmacılara özellikle farklı değişkenler ile yapabilecekleri çalışmalar için bir alt yapı ve bakış açısı sunulmaktadır.

\section{Sonuç}

Çalışan performansı konusunda ulusal düzeyde yapılan çalışmalar arasındaki bağlantı gücünün bibliyometrik analizi ilgili konudaki çalışmalara sistematik ve bütüncül bir bakış açısı oluşturma adına önemli görülmektedir. Bu çalışmada genel bir çerçeve çizildiğinde iki farklı bağlatıyı ortaya çıkarma amacı öne çıkmaktadır bunlardan ilki ile ilgili konu ve bu konuyla bağlantılı diğer değişkenlerin ve bu değişkenlerle birlikte çalışmaları yapmış yazarların ortaya koymuş oldukları araştırmaların niceliksel gücünü ortaya koymaktır. Bir diğeri ise araştırma alanlarına ilişkin net verileri paylaşarak çalışmacılar ve çalışmalar arasındaki ilişkilerin niteliksel bağlantılarını ortaya koymaktır. Buna göre; çalışmada TR Dizinde ulusal yazında yer alan çalışmaları incelenerek "Çalışan Performansı" konusunda başlık, özet ve anahtar kelime kısıtlarında "Çalışan performansı", "'İsgören Performansı" ve "İ̧s performansı" kavramlarının geçtiği toplam 221 araştırmanın bibliyometrik analizi gözden geçirilmiş̧ir. Bu çalışmalara bakıldığında özellikle 2015 yılına bir istikrar olmasa da 2015 y1lı itibari ile daha istikrarlı bir çizgiye geldiği görülmektedir. Özellikle son 5 yılda çalışanlar üzerinde yapılan performans araştırmalarının daha önceki 15 yıla kıyasla \%63,34'ünü kapsadığı görülmektedir. Bu durum özellikle yazın incelendiğinde İnsan kaynakları yönetimi alanında ve insanların çalışma performansı konusunda, endüstriyel sistemde değişim hızlandıkça artış yaşandığı anlaşılmaktadır. Dolayısıyla yapılan çalışmaların bu yönü, ilerleyen dönemlerde çalışan temelli konulara daha da ağırlık verileceği ön görüsünü oluşturmaktadır.

Bibliyometrik analiz sonuçları incelendiğinde çalışan performansı konusunda 116 farklı dergide yayın yapıldığı görülmektedir. Bu dergiler incelendiğinde ilk sırada 13 makale yayını ile İşletme Araştırmaları Dergisi’nin yer aldığı görülmektedir. $\mathrm{Bu}$ dergilerde yayın yapan 
araştırmacılara bakıldığında en çok araştırma yapılımış olan İşletme Araştırmaları Dergisi baz alındığında yapılan 13 çalışmanın hiçbirinde tekrar eden araştırmacının olmadığı görülmüştür. Bu çalı̧̧maların yıllara göre dağılımının ise 2020 yılında 4 adet, 2019 yılında 8 adet, 2018 yılında ise 1 adet olduğu tespit edilmiştir. Buradan hareketle son yıllarda çalışan performansı odağında insan üzerine yapılan çalışmalarda artışını destekler nitelikte bir görünüm söz konusudur. Bu verinin diğer bir sonucu ise bazı akademisyenlerin aynı konuda farklı çalışmaları olsa bile bunları farklı dergilerde yapma eğiliminde olduklarıdır.

Bibliyometrik analiz sonuçlarına göre, çalışan performansı konusunda en çok atıf alan çalışma 'Algılanan Güçlendirmenin İşgören Performansı Üzerine Etkileri'" başlıklı Çöl (2008) tarafından yapılan ve Doğuş Üniversitesi Dergisi'nde yayımlanan makaledir. Yazarın ve bu çalışmanın içerik ve diğer çalışmalar ile ilişkisine bakıldığında, farklı çalışmalarla toplamda alınan atıflara bakıldığında yazarın burada da sıralamaya girecek kadar nitelikli bir yayın ortaya koyduğu yönündedir. Bu noktada alanda tek çalışmayla en çok atıf alan 8 çalışmanın, toplam atıfların \%38,21'ini aldığı görülmüştür. Bu çalışmaların niteliğinin yanında çalışmaların yazın da temsil ettiği alanlar da önemli olduğu için bu çalışmaların içerikleri incelenmiş ve bu içeriklerin ÜAK'in belirlediği "yönetim strateji" içinde bulunan alanlardan daha çok insan kaynakları yönetimi ve örgütsel davranış yazınında yapıldığı görülmüştür. Ayrıca tüm çalışmalar için ortak yapılan atıfların birbirleriyle ilişkisi neticesinde mükerrer olanları çıkarıldıktan sonra elde edilen 1078 atfın, \%29,22'sinin yani neredeyse 3'te 1'nin en çok yayın yapan araştırmacılara ait olduğu görülmektedir. Bununla birlikte yazarlar ve yaptıkları yayınlar değerlendirildiğinde toplam 221 yayının 35'inde 10 araştırmacının ismi bulunmaktadır.

$\mathrm{Bu}$ araştırmada Türkçe alan yazınındaki çalışan performansı üzerine yapılmış çalışmalar derlenmiştir. Bu çalışmanın amacı farklı konularda yapılmış birçok bibliyometrik analiz çalışmaları gibi alanda farklı bir perspektif oluşturarak bir boşluğu doldurmak istemektedir. Bu boşluktan kasıt iki farklı yönde sunulmaktadır. Bunlardan ilki çalışma yapılan değişkenin ulusal dizindeki niceliğini ortaya koymaktır. Diğer yön ise bu niceliğin içinde gerek yapılmış atıf sayısı gerekse de yayın sonrası ilgili çalışmaların çeşitliliğini veren tablo grafik ve şekillerle nitelikli yanlarını aktarmaktadır. $\mathrm{Bu}$ amaç aynı zamanda insan kaynakları yönetimi altında ele alınan bu konuya dikkat çekerek bundan sonra yapılacak olan teorik, ampirik ve/veya nitel metotları içerecek tüm çalışmalara konu ile birlikte ele alınacak diğer değişkenler için yazarlara farklı bakış açısı sunmaktır. Ancak her çalışmada olduğu gibi bu çalışmanın da bazı kısıtları mevcuttur. Bu kısıtların en başında araştırma kapsamı ve araştırma için seçilmiş olan örneklem bakımında ulusal literatüre odaklanmasıdır. Bu odak nokta bir kısıt olmakla birlikte çalışmaya kendine özgü bir yan sunma çabasındandır. Örgütlerde çalışan performansının arttırılması, ulaşılması arzu edilen sonuçlar arasındadır. Bu bakımdan çalışmanın insan kaynakları yazını açısından sunduğu bu perspektif gelecekte ortaya koyulacak çalışmalarla, örneğin, eğitim-geliştirme, yetenek yönetimi, proaktif performans yönetimi, şeffaf ödüllendirme gibi İK uygulamaları ile genişletilebilir. Daha sonra ortaya çıkacak araştırmalar farklı değişkenler ile ilişki içinde verilerek disiplinler arası bir bakış açısıyla bu ve benzeri araştırmaları detaylandırarak yeni ilişki bağlantılarını ortaya çıkarabilir.

\section{Kaynaklar}

Al, U. \& Sezen, U. \& Soydal, İ. (2012), Hacettepe Üniversitesi bilimsel yayınlarının sosyal ağ analizi yöntemiyle değerlendirilmesi. Hacettepe Üniversitesi Edebiyat Fakültesi Dergisi, 29(1), 5371.

Al, U. \& Soydal, İ. (2012), Dergi Kendine Atıfının Etkisi: Energy Education Science and Technology Örneği, Türk Kütüphaneciliği, 26 (4), 699-714

Artar, A \& Bas, M. (1991). İşletmelerde Verimlilik Denetimi. MPM Yayınları; 13. 
Bayram, Ö. (1998), Atıf verisi (citation data) ve enformatik yasalar: Türk kütüphanecilik literatüründeki doktora tezleri üzerinde bir uygulama, Türk Kütüphaneciliği, 12(1), 21-32.

Bellek, M. \& Koparan, E. \& Aykan, E. (2019). Stratejik yönetim alanında Türkiye'nin genel durumu: 1975-2019 y1lları arası bibliyografik bir değerlendirme. Kayseri Üniversitesi Sosyal Bilimler Dergisi, 1(1), 58-90.

Çöl, G. (2008). Algılanan güçlendirmenin işgören performansı üzerine etkileri. Doğuş Üniversitesi Dergisi. 9(1).

Ertan, H. (2008). Örgütsel Bağlllık, İş Motivasyonu ve İş Performansı Arasındaki İlişki: Antalya da Beş Yıldızlı Otel İşletmelerinde Bir İnceleme. [Doktora Tezi], Kocatepe Üniversitesi Sosyal Bilimler Enstitüsü.

Hall, C. M. (2011). Publish and perish? Bibliometric analysis, journal ranking and the assesment of research quality in tourism. Tourism Management. 32, 16-27.

Karaman, R, (2009), İşletmelerde Performans Ölçümünün Önemi ve Modern Bir Performans Ölçme Aracı Olarak Balanced Scorecard, Sosyal Ekonomik Araştırmalar Dergisi, 1(16), 411-427.

Kurutkan, M. N. \& Orhan, F. (2018). Sağglk politikası konusunun bilim haritalama teknikleri ile analizi. İksad Yayınevi.

Liuch, J. O. \& Velasco, E. \& Lopez, M. \& Haba, J. (2009). Co 7 authorship and citation networks in Spanish history of science research. Scientometrics, 80(2), 373-383. Erişim adresi: https://link.springer.com/article/10.1007/s1119 2-008-2089-5

Motowildo SJ \& Borman WC \& Schmit MJ. (1997), A theory of individual differences in task and contextual performance. Human performance, 10(2), 71- 83.

Samiee, Saeed \& Chabowski, Brian R (2012), Knowledge structure in international marketing: a multi-method bibliometric analysis, Journal of the Academy of Marketing Science, 40(2), 364-386.

Seglen, Per O. (1994). Causal relationship between article citedness and journal impact. Journal of the American Society for Information Science, 45 (1), 1-11.

Tatar, C. C. \& Ece, A.S. (2012). Bilimsel dergilerdeki müzik makalelerinin bibliyometrik profili. Akademik bakış dergisi, Uluslararası Hakemli Sosyal Bilimler E-Dergisi, 30, 1-16.

Thelwall, M. (2008). Bibliometrics to webometrics. Journal of information science, 34(4), 605- 621.

Uyargil, C. (2013). Performans yönetimi sistemi bireysel performansin planlanması değerlendirilmesi ve geliştirilmesi, Beta Basım A.Ş.

Van Eck, N. J. \& Waltman, L. (2010). Software survey: VOSviewer, a computer program for bibliometric mapping. Scientometrics, 84(2), 523-538.

Sabuncuoğlu, Z. (2005). Insan kaynakları yönetimi uygulamaları, Alfa Aktüel Basımevi. 